Article

\title{
Adult Restorative Justice and Gendered Violence: Practitioner and Service Provider Viewpoints from Queensland, Australia
}

\author{
Samantha Jeffries *, William R. Wood and Tristan Russell (ic \\ Griffith Criminology Institute, School of Criminology and Criminal Justice, Griffith University, \\ Brisbane, QLD 4122, Australia; w.wood@griffith.edu.au (W.R.W.); tristan.russell@griffith.edu.au (T.R.) \\ * Correspondence: s.jeffries@griffith.edu.au
}

\section{check for}

updates

Citation: Jeffries, Samantha, William R. Wood, and Tristan Russell. 2021.

Adult Restorative Justice and

Gendered Violence: Practitioner and

Service Provider Viewpoints from

Queensland, Australia. Laws 10: 13.

https://doi.org/10.3390/laws10010013

Received: 11 January 2021

Accepted: 10 February 2021

Published: 17 February 2021

Publisher's Note: MDPI stays neutral with regard to jurisdictional claims in published maps and institutional affiliations.

Copyright: (c) 2021 by the authors. Licensee MDPI, Basel, Switzerland. This article is an open access article distributed under the terms and conditions of the Creative Commons Attribution (CC BY) license (https:// creativecommons.org/licenses/by/ $4.0 /)$.

\begin{abstract}
This paper presents findings from a study exploring the experiences and viewpoints of conventional criminal justice actors, social and legal service providers, and restorative justice (RJ) conference facilitators/convenors regarding the use of adult RJ conferencing in cases of intimate partner, domestic, family (IPDFV) and sexual violence (SV). Results indicated strong views about what IPDFV/SV victims needed from a system of justice, perceived failings of conventional justice systems in this regard, and the potential of RJ to deliver more efficacious justice. Nevertheless, using RJ in these cases posed concerns and challenges. Research participants identified steps that could be taken to overcome these issues through an RJ best practice framework underpinned by a victim-centred approach committed to victim empowerment, safety, healing, and practitioner training.
\end{abstract}

Keywords: restorative justice; domestic violence; family violence; intimate partner violence; sexual violence; gendered violence

\section{Introduction}

Intimate partner, domestic, family violence (IPDFV), and sexual violence (SV) constitute the most pervasive forms of gender-based violence, or violence against women, in Australia, and internationally (Australian Institute of Health and Welfare 2018; World Health Organization 2013). IPDFV /SV results in immeasurable physical, psychological, and material harms to victims; substantial costs to governments; and significant negative impacts on economic productivity and well-being (Commonwealth of Australia 2009).

Since the late 1960s, there have been increased efforts to reduce IPDFV/SV and improve responses to victims through legislative reforms, changes in conventional criminal justice policies and practices, and in the use of civil justice mechanisms. The dominant approach to addressing IPDFV/SV remains criminal justice sanctioning or civil protection orders (with the possibility of criminal consequence if breached) (Daly 2011). Yet, to date, there is limited evidence to suggest reforms and current approaches are working to reduce offending, increase efficacy of outcomes, or improve victim perceptions and experiences of justice (Daly 2011).

Support for restorative justice (RJ) as an alternative to conventional justice system responses to IPDFV/SV has gained traction over the last 25 years for its potential to augment victim efficacy and reduce offending (Cheon and Regehr 2006; Curtis-Fawley and Daly 2005; Daly 2011). Developed in the 1970s as an alternative to traditional juvenile court practices, RJ approaches seek to address and remedy harms caused by offenders by holding them directly accountable to victims and other relevant parties through facilitated dialogue. RJ programs are most often used as diversionary or post-adjudicative practices for youth offenders (Daly and Marchetti 2012). However, in the last two decades, RJ has increasingly been used for adult offenders, and for more serious or violent offences including IPDFV /SV (Daly and Marchetti 2012; Joudo-Larsen 2014; Wood and Suzuki 2016). 
Adult RJ conferencing for cases of IPDFV/SV has been operating in Queensland (Australia) since the early 1990s. The process involves a facilitated meeting between the person who caused the harm, the person/people who experienced the harm and supporters for both parties. Referrals to conferencing may be made by the courts, police, prosecutors, or corrective services, and participation in a conference is voluntary (Queensland Government 2019).

In this paper, we present findings from a qualitative study undertaken in Queensland exploring the experiences and viewpoints of practitioners (conventional criminal justice actors and RJ practitioners) and IPDFV/SV service providers (social and legal) regarding the use of adult RJ conferencing in cases of gender-based violence. Specifically, from the perspective of these practitioners and service providers we sought to: (1) understand what victims of IPDFV/SV need from a system of justice; (2) discern the perceptual benefits and challenges of utilising adult RJ conferencing in IPDFV/SV cases; (3) establish what a best practice adult RJ conferencing framework might encompass; and (4) identify the potential training needs of RJ conference facilitators/convenors. Following our review of prior research literature and discussion of methodology, we present our research findings and conclude with discussion of identified challenges and risks in using RJ for IPDFV/SV, as well as a summary of suggestions on how these can be best mitigated.

\section{Literature Review}

Previous research has demonstrated several needs regularly reported by IPDFV/SV victims regarding justice and the justice system. These include: (1) establishing a sense of power and control by telling their story, being heard, having input into a resolution, and being able to ask and receive answers to their questions; (2) receiving an acknowledgment of wrongdoing from the offender, reparation, and reassurances of future safety for themselves and others; (3) having a process that counteracts the isolation and trauma experienced in the aftermath of their victimisation (i.e., by not victim blaming, silencing, or trivialising their experience); (4) being provided with an environment that protects their physical and emotional safety, and does not re-victimise or re-traumatise them; and (5) having ready access and support from a justice system that works effectively to reduce revictimisation and offending against others (Daly 2011; Stubbs 2002). Conventional justice practices have not made significant inroads into meeting these needs and there is advocacy for reform. Since at least the late 1980s, there have also been increasing calls for alternatives to, or innovative justice mechanisms (Centre for Innovative Justice 2014; Daly 2011). RJ is one such approach (Daly 2011; Stubbs 2002).

Advocates for the use of RJ for IPDFV/SV argue that the informal and flexible processes are better positioned than conventional justice to validate, empower, and heal victims through the provision of a safe space where victims are given a voice, have opportunity to confront the offender, and have input into justice outcomes (Centre for Innovative Justice 2014; Cheon and Regehr 2006; Daly 2011; Koss 2006; Miller and Iovanni 2013; Stubbs 2004). Many advocates also argue that RJ is beneficial in providing an environment that can be sensitive to victim needs and issues, such as trauma and mental health problems, that are frequent for victims of these offences (Hopkins et al. 2004; Koss 2006; Miller and Iovanni 2013; Stubbs 2004).

It is also suggested that RJ may contest and potentially change normative constructions around IPDFV/SV (Cheon and Regehr 2006). Through victim validation and thwarting of victim-blaming, RJ may be more effective in holding offenders to account for denials or minimisations of harms (Cheon and Regehr 2006; Curtis-Fawley and Daly 2005; Miller and Iovanni 2013; Proietti-Scifoni and Daly 2011). Moreover, RJ may challenge community misconceptions about IPDFV/SV (e.g., that victims are somehow complicit in their abuse) (Cheon and Regehr 2006; Wager 2015). The informality and flexibility of RJ may allow it to be adapted to victims' and offenders' individual needs, enabling a more holistic understanding of, and response to, IPDFV/SV (Jülich and Thorburn 2017). Finally, RJ is seen by some as having the potential to address violence for those who wish to continue the 
relationship with the perpetrator (Miller and Iovanni 2013; Proietti-Scifoni and Daly 2011; Wager 2015). However, these potential benefits of using RJ in IPDFV /SV cases have been widely challenged or cautioned by many scholars, practitioners, and victim advocates. This is discussed in more detail below.

In contrast to most other types of offences, gender-based violence is often characterised by historical and ongoing victim-offender power imbalances. IPDFV/SV is rarely a one-off incident, offenders are often not strangers, and victims frequently experience on-going abuse over protracted periods (Hudson 2002; Miller and Iovanni 2013; Stubbs 2010). SV, even if it is a one-off incident, is also an aggressive act motivated by gendered power and control (Hudson 2002). IPDFV/SV also frequently involves highly manipulative perpetrators who are inclined to abnegate accountability/responsibility, victim blame, minimise their actions, and be empathetically deficient (Cheon and Regehr 2006; Hopkins et al. 2004; Miller and Iovanni 2013; Stahlman 2017). IPDFV /SV commonly causes harms that are wide-reaching and long-standing, with victim trauma, distress, and feelings of shame being especially high (Bennice et al. 2003; Beck et al. 2011; Buchbinder and Eisikovits 2003; Cheon and Regehr 2006, pp. 378-79; Enander 2010; Jones et al. 2001). Finally, IPDFV/SV offences are often tacitly or even openly supported by societal and community gender norms that permit or encourage gender inequality, and offenders' power and control of victims (Alexander-Scott et al. 2016).

These issues present challenges for the use of RJ in IPDFV/SV cases. Specifically, there is danger of gendered power imbalances being replicated in RJ's informal process, particularly where face-to-face meetings may afford offenders an opportunity to assert ongoing forms of verbal and non-verbal control, even if subtly. RJ may provide a continued forum for the micro-dynamics of violent and abusive relationships, which may not even be recognised or perceived by conference facilitators/convenors or others who are present (Miller and Iovanni 2013; Proietti-Scifoni and Daly 2011; Silvester 2015). There is also concern that the informal nature of the process will be manipulated by offenders and their supporters, allowing them to minimise harm and victim blame. Family and friends (who can be present during the RJ process as supporters to victims and offenders) may also have mixed loyalties regarding the victim and offender (Miller and Iovanni 2013; Proietti-Scifoni and Daly 2011; Silvester 2015). Such gendered power differentials may heighten risks to victim safety, including re-victimisation and associated trauma before, during, and after the RJ process (Miller and Iovanni 2013; Proietti-Scifoni and Daly 2011; Silvester 2015; Stubbs 2004).

There are also concerns around victim voluntariness and ability to freely, fairly, and effectively participate in RJ. IPDFV/SV victims may be pressured into participation by perpetrators and coerced into agreements (Edwards and Sharpe 2004; Stahlman 2017). Victims with histories of trauma and ongoing fear may not be at liberty to advocate successfully on their own behalf, and will have learned over significant periods of victimisation they must comply with perpetrator wishes and subvert their own in order to avoid further violence (Edwards and Sharpe 2004; Hooper and Busch 1996; Silvester 2015; Stahlman 2017). Additionally, enmeshment with perpetrators (i.e., economic, emotional, shared parenting responsibilities) may restrict free choice and participation (Hopkins et al. 2004; Silvester 2015; Stahlman 2017; Wager 2015).

There is also concern that IPDFV will be constructed in RJ processes as a problem of 'conflict' ownership or conflict-resolution within relationships or that RJ will approach IPDFV/SV as a 'one off' incident by focussing only on the offence that resulted in the process being initiated (Stubbs 2010; Wood and Suzuki 2020). This is problematic in IPDFV and many cases of SV because violence is frequently recurrent and escalates over time (Stark 2009). Similar concerns have been raised about the focus within some RJ practices on 'restoring' relationships, which may pressure victims of IPDFV or SV into being responsible for changing the perpetrator or reconciling the relationship for the sake of the offender or shared dependants (Mills et al. 2009; Silvester 2015). Such victim responsibility may, in turn, result in victim-blaming discourses or undo focus on discussion of agreements 
where harms done to victims may be minimised (Silvester 2015; Stahlman 2017; Presser and Gaarder 2000).

The role of and focus on apologies in RJ processes also presents unique challenges in cases of IPDFV/SV. Perpetrators are commonly unwilling to take personal responsibility for their behaviour (Cheon and Regehr 2006; Hopkins et al. 2004; Miller and Iovanni 2013; Stahlman 2017). This may create problems in cases where offenders use apologies to neutralise accountability for their actions, or where there are expectations placed on victims to accept apologies or forgive the offender, particularly when the victim is responsible for the well-being of shared children, other dependents, and family members (Silvester 2015; Stahlman 2017). Apologies in the milieu of IPDFV are also problematic because many victims will have previously experienced this as a tactic of control used by offenders in the cycle of abuse. Thus, apologies provided in RJ may be inauthentic and/or serve to perpetuate IPDFV (Miller and Iovanni 2013; Silvester 2015; Stubbs 2010). In the context of SV, moreover, Koss (2006, p. 233) has noted that, "it is not appropriate to expect that a rapist who apologises, compared to a burglar, will or should be believed or that forgiveness could or should occur."

Additionally, there is apprehension that the informal and dialogue-driven aspects of RJ may provide offenders with readymade access to victims. This is especially problematic in IPDFV where the relationship has ended, or when the victim is attempting to end it. Offenders may use RJ to gain information about victims, attempt to convince victims to return to harmful relationships, re-gain power and control over victims, or threaten or menace victims in subtle ways (Silvester 2015). In cases of SV, Wager $(2015$, p. 17) also notes that rather than "developing empathy and a commitment to do no harm," sexual offenders "can experience excitement on hearing their victim tell of the distress they successfully inflicted," and may use the opportunity to meet with the victim to elicit further satisfaction from their offences.

There are misgivings that a one-off RJ meeting will make any headway in changing pervasive and entrenched social and gender norms, reduce offending, or provide safety and healing to victims. Further concern has been raised over the role and function of the community in RJ when community responses to IPDFV/SV are often severely underresourced, and when there is societal tolerance of these offences (Proietti-Scifoni and Daly 2011). Community participation in RJ may reinforce rather than challenge male dominance, associated violent behaviour, and victim blaming (Coker 2006; Edwards and Sharpe 2004; Miller and Iovanni 2013; Proietti-Scifoni and Daly 2011; Silvester 2015). Moreover, critics note that RJ's emphasis on community re-integration is problematic when these very communities may have been complicit in or even condoned such violence (Coker 2006; Edwards and Sharpe 2004; Silvester 2015).

Finally, there are other implications that can be broadly characterised as socialstructural and symbolic. First, RJ's informal processes may be perceived as a re-privatisation of IPDFV/SV, particularly where feminist scholars, practitioners, and advocates have spent decades fighting to make gendered violence a visible political and criminal justice priority. RJ may thus represent an opportunity for the state to divert responsibility from directly addressing and adequately funding appropriate and effective responses to IPDFV/SV, placing the problem back on communities and, in particular, low-paid or volunteer service providers who are most often women. Second, there are concerns that RJ may be construed as too lenient and send the wrong message to offenders, potential offenders, victims, and communities that IPDFV/SV is not responded to or dealt with on the same level as other serious violent crimes (Hudson 2002; Miller and Iovanni 2013; Mills et al. 2009; Proietti-Scifoni and Daly 2011; Silvester 2015; Stahlman 2017).

Compared to the larger amount of theoretical or speculative research on the use of RJ for IPDFV/SV (discussed above), there remains a smaller number of empirical studies that have examined the perspectives of conventional criminal justice actors, RJ practitioners, and IPDFV/SV service providers involved in the delivery of RJ for these cases. To our knowledge, there are only six peer reviewed studies published to date in English (Curtis- 
Fawley and Daly 2005; Gavrielides 2015; Nancarrow 2006; Proietti-Scifoni and Daly 2011; Rubin 2009) that have investigated people's perceptions of the use, efficacy, and problems of RJ in cases of IPDFV /SV for adult offenders. However, only two studies have included RJ practitioners' viewpoints (Gavrielides 2015; Proietti-Scifoni and Daly 2011).

In Australia, Curtis-Fawley and Daly (2005) conducted $n=15$ interviews with victim advocates to assess perceptions of RJ in cases of IPDFV/SV. Findings revealed opposing views about RJ's suitability. Those with greater exposure to, or familiarity with, RJ were more likely to support it than those with less RJ exposure. Most participants cited some benefits to RJ for IPDFV/SV. These included the potential of RJ to provide more innovative responses; support victims to maintain relationships with offenders (where desired); afford victims a voice, and a chance to be heard; constructively address power imbalances; offer a forum in which offenders can acknowledge responsibility/admit guilt; and keep victims out of the conventional justice system, which was perceived to be failing (Curtis-Fawley and Daly 2005, pp. 619-28).

Participants also expressed reservations that RJ would not live up to its ideals, and mentioned several specific concerns (Curtis-Fawley and Daly 2005). First, power imbalances may be difficult to address in an informal RJ process, and the potential for re-victimisation will be high. Facilitator/convenor skills may alleviate this problem. Second, RJ might be construed by offenders and communities as an easy option or too lenient of a response. Third, RJ may re-privatise gender-based violence, jeopardising "decades of work to raise social awareness and to make legal authorities take violence against women and children seriously" (Curtis-Fawley and Daly 2005, pp. 625-26).

Nancarrow (2006) conducted a comparative qualitative study of Indigenous and non-Indigenous women's views on the efficacy of RJ in IPDFV cases. Interviews were conducted with $n=20$ women ( $n=10$ Indigenous women, $n=10$ non-Indigenous women). Women were either members of an Australian Taskforce exploring criminal justice system responses to gendered violence, or worked with victims. No Indigenous women preferred the conventional justice system. Most $(n=6)$ preferred RJ. In contrast, most non-Indigenous women $(n=6)$ favoured conventional justice over RJ.

Indigenous women's support for RJ rested on two platforms. First, women saw conventional justice as a tool of Indigenous oppression, and a facilitator of increased violence against women and Indigenous communities. Second, central to Indigenous women's concept of RJ was, "the promise of an element of self-determination for Indigenous people" (Nancarrow 2006, p. 94). Indigenous women's support for RJ was conditional on it being a self-determined, grassroots, holistic initiative with Elder control (Nancarrow 2006, p. 100).

Non-Indigenous women were wary of RJ because IPDFV is "fundamentally different from other crimes" (Nancarrow 2006, p. 98). There was unease that IPDFV would be trivialised, minimised, and that RJ would fail to communicate the unacceptability of these crimes. Safeguards were needed to protect women from being coerced into RJ, and to ensure informed participatory decision making. It was also expressed that RJ should not be used when violence is ongoing (Nancarrow 2006, pp. 98-99).

In Canada, Rubin (2009) undertook focus groups and interviews with $n=125$ women (IPDFV/SV advocates and victims). The research impetus was a government proposal to implement RJ in lieu of conventional justice to better address misogynistic violence. The government's proposal had been met with resistance from women's advocacy groups because there was no consultation or supporting research evidence. Critics noted the RJ proposal had not considered the safety, power, and control issues specific to gender-based violence, nor contemplated the necessary security measures before, during, and after RJ (Rubin 2009, p. 3). Furthermore, the government's proposed initiative was to be managed by actors from the conventional criminal justice system (i.e., police, prosecutors, judges, social workers, etc.). Participants feared that old patterns of ignorance about IPDFV/SV and discrimination against women would continue or become worse. There was also 
concern that, as RJ is more informal, criminal justice actors would have wider discretion and be subject to less scrutiny.

Participants in Rubin (2009) study also expressed concern for women's safety before, during, and after RJ. Of concern were cases where perpetrators and victims continue to reside together, have contact related to children, or ongoing interaction for other reasons. Following on this, there was concern that, where women had exited abusive relationships, offenders could use RJ to gather personal information about them. Unease was similarly expressed regarding the safety of victims' children, other family, and community members that offenders may retaliate against. Further issues raised regarding victims' safety included women being pressured into participating in RJ by offenders, families, communities; victimblaming; and a lack of attention to victim trauma. Finally, there was fear that victims of IPDFV/SV may not have a support network to call on, due either to social isolation (a tactic used by abusive men to control their victims) or because communities may be complicit or condone the violence (Rubin 2009, pp. 5-13).

In New Zealand, Proietti-Scifoni and Daly (2011) interviewed $n=19$ opinion leaders (i.e., those who worked in government, headed major victim service organizations, or provided victim support or RJ facilitation). Three groups emerged: supporters, sceptics, and contingent thinkers. Supporters generally embraced RJ for IPDFV/S, but discussed the need for additional provisions if RJ was used for these crimes. Supporters cited "healing, active participation, and the ability for victims to voice their experiences" (Proietti-Scifoni and Daly 2011, p. 278) as reasons for their backing. However, they recognised that using RJ in cases of on-going offending was more challenging than for discrete offences with less complex interpersonal dynamics (Proietti-Scifoni and Daly 2011). Overall, their support was conditional on the following elements being in place: victim voluntariness; informed decision making; safety and support, both during and after the RJ process; adequate preparation of victims and offenders; and experienced and well-trained facilitators/convenors who understood on-going power dynamics (Proietti-Scifoni and Daly 2011).

Sceptics expressed minimal support of RJ for IPDFV/SV. Victim safety and on-going power dynamics were focal points. However, some did suggest RJ might be acceptable in relationships that were not characterised by on-going controlling violence/abuse. Overall, sceptics supported RJ ideals, but doubted these would translate into practice (Proietti-Scifoni and Daly 2011). Contingent thinkers were largely supportive, but expressed misgivings about the difficulties of employing RJ where interpersonal violence was ongoing. Discrete acts of SV presented as the most amenable. This group had more caveats around the translation of RJ into practice. They wanted additional protections and conditions, including victims being fully informed; voluntary participation; victim safety; and having support and facilitators/convenors with extensive skills in addressing power imbalances (Proietti-Scifoni and Daly 2011).

Participants were also asked what was needed to restore the harm of IPDFV/SV victimisation, and to share their vision of what an RJ program serving victims' needs would look like. The following were suggested: (1) a women-centred approach that incorporates victim and IPDFV/SV advocate knowledge in the planning and development of RJ programs; (2) having female facilitators/convenors with lived experiences of IPDFV/SV victimisation so that expertise could be assured; (3) safety planning before, during, and immediately subsequent to RJ; (4) long-term and on-going post-RJ follow up; and (5) that a broader understanding of endangerment was needed beyond an incident-specific approach. Thus, information pertaining to the history of violence should be considered (i.e., for the current victim and any previous victims) (Proietti-Scifoni and Daly 2011).

In the United Kingdom, Gavrielides (2015) sought RJ practitioner, victim advocates, service providers, and victim views of RJ in cases of IPDFV using semi-structured interviews $(n=10)$ and focus groups ( $n=22$ participants). Results showed a belief that RJ could be beneficial to victim empowerment and meeting their needs/wishes. However, the unique features of IPDFV resulted in the following suggestions: (1) flexibility of process, for example, it does not always have to involve a face-to-face meeting; (2) inclusion of 
IPDFV risk assessment tools in the preparatory phase; and (3) holistic victim support (i.e., therapy, connections to IPDFV /SV agencies) pre- and post-RJ.

Nettleton and Strang (2018), also in the United Kingdom, explored the likelihood of IPDFV victims and offenders $(n=75)$ agreeing to participate in RJ. They found that $41 \%$ of victims and $25 \%$ of offenders indicated that they would participate in RJ if offered to them. Victims and offenders with some reason for ongoing contact with each other tended to be more interested in RJ than those who had ended the relationship. Victims reporting lower levels of fear of the offender, and those who self-reported fewer prior offences being committed against them, were more willing to participate in RJ.

In many respect the results from these studies reflect debates discussed previously, namely that RJ in cases of IPDFV or SV has promise, but translation into practice poses numerous challenges that must be handled with care. This is not surprising, as much of the theoretical work or debates have been written by feminist scholars, victim advocates, or practitioners that have significant experience with IPDFV or SV offending, victimisation and the use of RJ broadly, and specifically in the context of these types of offences.

Nevertheless, such empirical research is important and necessary. RJ programs vary significantly by type and region, and, as such, it is not possible to make broad claims about strengths or weaknesses of RJ for use with IPDFV/SV without a suitable body of empirical work that has investigated these claims. Our research seeks to add to this small body of empirical knowledge to investigate the 'fit' or resonance of the debates we have discussed above within the use of RJ for IPDFV/SV in Queensland. Moreover, while the role of RJ facilitators/convenors in facilitating RJ practices and outcomes is frequently discussed in research, as Suzuki and Wood (2017) note, there remains far less research on facilitator/convenor perspectives and experiences, even where facilitators/convenors often have the most comprehensive understanding of cases from preparation to final outcomes, as well as knowledge of administrative issues or constraints that impact RJ delivery. Our research included interviews with conventional criminal justice actors, social and legal IPDFV/SV service providers, and RJ conference facilitators/convenors regarding their use and experiences with RJ for IPDFV/SV cases, and thus seeks to add to knowledge in this area as well.

\section{Methodology and Research Participants}

In-depth semi-structured interviews were conducted with $n=12$ research participants. This included: $n=6$ RJ practitioners (i.e., conference facilitators/convenors or those providing therapeutic support to conference participants), $n=2$ conventional criminal justice actors with adjunct experience of RJ and gender-based violence, and $n=4$ social and legal service providers supporting victims of gender-based violence.

Interview topics consisted of research participants' responses to broad discussion topics relating to their views about: (1) what IPDFV /SV victims need from a justice system; (2) the capacity of conventional justice to respond to IPDFV/SV; (3) the benefits and challenges (possible or actual) of using RJ for IPDFV /SV; (4) RJ best practice for these types of offences; and (5) facilitator/convenor training needs. These broad discussion topics were developed from the key themes identified in the prior literature on RJ and gendered violence (as discussed above).

Research participants were identified by researchers in conjunction with the manager of the Adult RJ Program in Queensland. A purposive sampling strategy was used, identifying participants that were likely to have knowledge of, or experience with, RJ in IPDFV/SV cases. Researchers also sought to involve participants outside of RJ practice, including relevant conventional criminal justice system actors, and IPDFV /SV service providers. Participants were recruited via email, provided with an information sheet overviewing the purposes of the research, and informed consent forms, which were then signed prior to the interviews taking place. To ensure anonymity and confidentiality, all interviewees have been deidentified. Numbers and letters are used to denote the research participants from each other. More specially, RJPs are RJ practitioners, CCJs are conventional criminal 
justice actors, and SLSs are IPDFV/SV legal or social service providers. Ethical approval for this research was obtained from Griffith University's Human Research Ethics Committee (protocol code GU Ref No: 2020/397).

All interviews were conducted in person, or through Microsoft Teams or Zoom. Interviews were recorded and lasted between 1.5 and 2 hours. The interview recordings were transcribed verbatim and analysed thematically, using NVIVO, under the discussion topic headings outlined above. Analysis was in the first instance deductive because interview transcripts were organised under the discussion topic headings. However, inductive coding then took place within and under these overarching discussion topics to identifying distinct themes within the participants' narratives. The analysis was led by the first author. Themes identified were then discussed amongst the research team members, all of whom were involved in participant interviews, analysis, and reporting. Below we present our findings from the thematic analysis of the interview transcripts under each of the interview topic headings.

\section{Victims' Justice Needs}

According to interviewees, victims of IPDFV/SV commonly express several justice needs. These include: (1) to establish a sense of power and control by telling their story, being heard, having input into a resolution, and being able to ask and receive answers to their questions; (2) to receive an acknowledgment of wrongdoing from the offender, a demonstration of accountability, commitment to change, reassurances of future safety and reduced offending; (3) to have a justice process that counteracts the isolation and trauma experienced in the aftermath of their victimisation (i.e., by not victim blaming, silencing, or trivialising their experiences) and does not re-victimise or re-traumatise them. We discuss each of these points in detail below.

\subsection{Empowerment and Control}

Interviewees explained that, for victims of gender-based violence, the "number one factor" (RJP3), or what they needed most from a justice system, was a sense of power within, and "control over the process" (SLS1). As explained by SLS1, gender-based violence is "about power and control" and, as such, this should not then "continue to be play[ed] out in a justice process." Empowerment for victims of gender-based violence means opening a space where they can give voice to the harm caused, and perpetrators are positioned to listen. It also necessitates extending victims the opportunity for input into justice outcomes in accordance with their experiences. Justice systems should be flexible, because, as explained by CCJ2, the needs of victims "can be different, depending on the person." Finally, interviewees explained that victims are more likely to feel a sense of power and control when a justice process extends them the opportunity to ask questions of the perpetrator. RJP1 relayed, victims need "understanding to make sense [of what happened to them, they] need to engage in meaning making, an understanding of their own experience through being able to ask and receive answers to their questions."

\subsection{Acknowledgement of Wrongdoing, Accountability, Change, Reduced Offending and Future Safety}

Participants described victims' needs for a system of justice where victims can receive an acknowledgment of wrongdoing from the offender. RJP1 expressed, "it is about accountability." Victims need the offender to "stand up" and say, "I admit it," because so often in cases of gender-based violence, men are "denying it to everybody," which then "compounds the issue." However, participants noted that victims also want accountability demonstrated through offender action. RJP4 explained that victims need to see offender engagement with behavioural change because "it's about trying to get that offender to look at their behaviour. There needs to be more [behaviour change/program] intervention. More work put into trying to make [offenders] accountable and manage their own behaviour." Victims of IPDFV /SV want perpetrators to "stop victimising and abusing" 
(SLS1). They need, "some reassurances about their safety moving forward so they won't be further victimised" (RJP1).

\subsection{Isolation, Re-Victimisation and Trauma}

Interviewees expressed that, in the aftermath of IPDFV/SV, justice systems should not exacerbate victim isolation and trauma. Victims should not feel as though they are being blamed for what has happened to them, and their experiences should not be trivialised or silenced. As explained by RJP1, victims need to be "believed and validated". In addition, victims require a justice system that is accessible, and emotionally and physically safe. SLS1 relayed that victims "need a safe [justice] process that feels accessible ... and that the requirements of that process are not in complete contradiction to healing and recovery." Interviewees argued that the provision of advocacy and support services pre, during, and post the justice process were "high on the list of what they [victims] require" (RJP6). These measures are important to counteract victim isolation and trauma, increase safety, and decrease the likelihood of re-victimisation and associated harm. RJP4 explained that you need to be "wrapping services around the victim" to improve safety.

\section{Conventional Justice Systems}

All interviewees expressed serious concerns about the ability of the conventional justice system to meet the needs of IPDFV/SV victims. RJP3 expressed this general discontent by saying, "my sense is that, if I was going to be a victim, I really wouldn't want to be a victim of gendered violence that's proceeding to the court process." The conventional justice system was described as offender-centric, ridged, protracted, and "unhelpful and hostile for victims" (RJP3). More specifically, interviewees described a system in which victims lacked input and control, were disempowered through mechanisms of silencing, re-victimised, re-traumatised, and unsupported. The system itself was described as an extension of power and control and an avenue for further abuse. Accountability and perpetrator behavioural change were lacking, and as such, victims had no reassurances of safety. Each of these points is discussed in more detail below.

\subsection{Victim Disempowerment and Lack of Control}

Interviewees described conventional justice as a disempowering process for IPDFV /SV victims because their voices were silenced, they had minimal input into what was taking place, and were rarely communicated with. RJP5 and SLS1 explicated that victim silencing was a problem with police that "pushed" gender-based violence "under the carpet" or engaged in "victim-blaming." In the courts, victims "become witnesses in a criminal matter" (CCJ2). CCJ2 explained, "they're silenced and kept to the side until they're required", and then, as SLS1 stated, "as witnesses to the crime, defence tactics are predominantly aimed at diminishing the character and reliability of victims". Thus, as narrated by SLS2, by confining victims' voices "to cross-examination; their story and their narrative is not heard within the courtroom. They're basically invisible in the process." Additionally, SLS1 explained that conventional criminal justice actors rarely communicated with victims. She said, victims "don't have control over the processes unfolding. They don't have any information and that just adds this whole extra layer of feeling totally disempowered."

\subsection{Re-Victimisation, Trauma and Limited Support}

Rather than providing a space where victims of IPDFV/SV are believed, validated, and extended safety and the opportunity to heal, the conventional criminal justice was described as re-victimising, traumatising, abusive, and an extension of power and control. RJP4 relayed,

"my issue with the whole thing (gender-based violence) is that it's always about power and control. Still we have a system that's about power and control. The victim if you like has been going through this process of control and power over and over and then they end up in a system which is still trying to control and put power over them." 
SLS3 stated, "it [conventional justice system] is just abusing women basically. As an offender focussed system, conventional justice could also facilitate and act as a conduit of further abuse by for offenders."

The conventional justice system was described by interviewees as trauma inducing, not trauma informed. RJP5 described it as a "sterile [and] de-humanising [system] lacking empathy [and] exacerbating the trauma already experienced." SLS3 noted,

"basically, our clients are traumatised by the act of violence and their own trauma is used against them in the process. I think that whole process of the criminal justice approach; the cross examination, the reporting to the police. It's just so overwhelming and shocking."

Thus, conventional justice was viewed as adding to victims' trauma, and interviewees expressed concern that victims were not being extended the support needed to navigate, and psychologically survive the process. SLS3 narrated that victims,

"don't have support through the system. The whole criminal justice system was [not] set up to deal with highly traumatised people in the sexual violence realm and in domestic violence where you've got an ongoing relationship. It's really the setup for strangers in a pub; they fought one another on a night out when they got on the piss and they really don't have anything to do with one another ever again."

\subsection{Lack of Offender Accountability and Change}

Achieving offender accountability through conventional justice was construed by interviewees as a rarity for two reasons. First, the likelihood of an actual response (i.e., legal redress) is minimal. SLS3 explained that perpetrators of IPDFV/SV "know they can get away with because there is no accountability." Interviewees expressed that victims were acutely aware of the justice system's failing in this regard, which resulted in them not wanting to report further victimisation. CCJ2 explained that victims of IPDFV/SV often did not see "that the perpetrator" was being "held to account." There were no "consequences for their behaviour," and as such, is there "any real point or benefit in them [victims] coming forward?" Second, even when conventional criminal justice responses are forthcoming, this could actually "endanger them [victims] more" because conventional justice was weighted toward "retribution," which meant "accountability, healing, and recovery for perpetrators" was negated (SLS1). In other words, behavioural change was unlikely to occur within a system weighted toward punishment and control and devoid of rehabilitative opportunity. Some interviewees argued that responses like imprisonment and protection orders may, in fact, cause an escalation of the violence and put victims at further risk.

\section{Benefits of RJ}

Participants identified several benefits or improvements offered by RJ over conventional justice responses to IPDFV/SV victims. These included: the use of RJ as a more viable way for victims to have an input; an environment for victims that was less intimidating, comparatively safe, and more amenable to opening space for victim validation and empowerment; increased opportunities for victims to have a 'voice;' and the opportunity to confront their perpetrator and hold them accountable in a more supportive victim-focused environment. CCJ2 explained that,

"some victims do want the opportunity to face the perpetrator. [With RJ] they get the opportunity to face them and really tell them what the impact has been of their violence on them. Some people, particularly with relationships, they find that gives them some level of closure. I think that would be the benefit-it's having them feel like they have a voice and getting to put that forward to the perpetrator. Empowering the victim and making them feel like they've got something out of the process."

SLS2 stated that RJ "could be very validating [for victims] because when [you] name behaviours for women [e.g., IPDFV], they feel validated. They thank you for actually seeing the behaviours for what they are and that it's not their fault." SLS3 said, RJ explicated that 
offenders "have done wrong. It provides a level of acknowledgement [and] accountability that they may not get in a criminal justice approach."

Thus, RJ was viewed by some participants as more aptly situated to censure and hold IPDFV/DV perpetrators accountable, and also affording the perpetrator more opportunity to demonstrate accountability through behavioural changes and the making of amends. As we discuss in more detail in the next section, however, these benefits were offered cautiously by many interviewees, who often voiced a realistic view that RJ alone was not likely to achieve these benefits unless there was clear intent for perpetrators to use the RJ process as part of a broader attempt to understand and change their behaviours.

In terms of offender accountability, one of the primary benefits noted by several RJ facilitators/convenors was that the RJ process afforded them the opportunity to more fully vet and determine offenders' abilities to take accountability and motives for participation prior to the conference. Several interviewees noted that they would discontinue the conferencing process if they had doubts about either. However, pre-conference preparation was also identified as a primary place where facilitators/convenors were able to explain and discuss what was expected from offenders in terms of accountability, and this was seen not only as necessary to ensure victim safety, but also an opportunity for offenders to more fully understand what was required and what may be asked of them to more fully take responsibility for the harms they had caused.

Regarding the conferencing process, interviewees explained that offenders should face their victim, and listen to the consequences of their actions. This was seen as an opportunity to be accountable directly to victims in ways that would not be readily available in conventional court processes. It was also viewed as an opportunity to confront perpetrator denials or minimisation of harms when they occurred, and explain to offenders in dialogue how and why such harm minimisation was problematic. Several RJ facilitators/convenors noted that pre-conference preparation was vital in instances where offenders denied or minimised harms to victims. In conference they would often refer the offender back to what had been discussed and agreed upon in pre-conference meetings regarding accountability expectations. In this regard, one strength identified in the RJ process was the ability of facilitators/convenors to help offenders align their 'backstage' work on accountability in pre-conference meetings with their 'performance' of accountability in the conference itself.

In addition, interviewees explained that in RJ cases for IPDFV/DV, there was frequently an expectation that accountability should translate into actual behavioural change, not merely apologies or amends. SLS1 noted, "I think that it reinforces accountability by making him more visible. Him having to take steps towards behaviour change." Unlike conventional justice, there is "wraparound support for the offender' [e.g., access to perpetrator behavioural change programs]. Thus, SLS1 continued, "I feel that RJ could be a movement towards putting the focus on him and his behaviours and what he can do to address his behaviours."

RJ was also seen by some interviewees as challenging and potentially changing broader societal misconceptions about IPDFV/SV because victims are given a voice and validated, victim-blaming is thwarted, and perpetrator denials or minimisations challenged. RJP2 narrated that, in her experience, RJ worked well in cases of SV because it enabled "the victim to kind of really have a voice. The victim really was coming from a broader community or female concern in that I want to make sure that this person understands that what they did is not acceptable. To challenge some of those broader kind of views about women and how you interact with women and what's acceptable."

Finally, interviewees noted that the informality and flexibility of RJ allowed it to be adapted to victims' (and offenders') individual needs, enabling a more holistic understanding and response to IPDFV/SV. RJP2 stated, "what is great about it is that it's so flexible- there's a lot of flexibility within it to attend to everyone's needs." RJP1 noted that some victims chose to attend only parts of their conference that were important to them, while letting the facilitator/convenor or other advocates conduct other parts where they did not want to be present. Other interviewees also noted they explained to victims 
that the conference could be amended to their needs. RJP1 explicated how, in the case of SV offences, they regularly shortened or eliminated the "storytelling phase" of the conference, so that the victim did not have to relive the events of their victimisation from the perspective of the perpetrator, and so that the perpetrator did not have the opportunity to use this to gain further satisfaction from their offences.

\section{The Challenges of RJ}

Despite the promise and potential benefits outlined above, interviewees still voiced that utilising RJ in cases of IPDFV/SV was not without challenges. These can be categorised under the following headings, and are discussed in detail below: (1) gendered power imbalances, re-victimisation, harm, victim voluntariness; (2) perpetrator accountability and apologies; (3) one-off incident; (4) facilitator/convenor neutrality; (5) broader socialstructural and symbolic implications; and (6) Indigenous Peoples.

\subsection{Gendered Power Imbalances, Re-Victimisation, Harm and Victim Voluntariness}

Interviewees explicated concern that the inherent power imbalances characterising IPDFV /SV could be replicated in RJ. SLS3 said,

"I just think we have to be extremely careful and aware of the dynamics of power and control and that these perpetrators are highly manipulative, quite charming and is this [RJ, being used as] just another process of abuse. If you don't understand the dynamics of violence and how manipulative and how cunning some of these blokes are then [you risk] colluding with him in his ongoing violation of her."

Power imbalances, and the especially manipulative ways in which these types of offenders operated, raised concerns around the possibility of re-victimisation and harm being caused during, or as a result of the RJ process. CCJ2 was uneasy about "on-going levels of power and control," and perpetrator manipulation. It "may look as though they are willing to participate, but you don't know what the triggers are for somebody [victim] when there has been ongoing use of power and control over years and years. One word [from the perpetrator during an RJ process], which may not seem offensive to you or me, in a relationship like that could have a completely different meaning." CCJ1 noted, "I get concerned about the power and control aspect. Even if they [victims] agree to participate in the process-would they really feel empowered by it, or would it be a way for the perpetrator to further victimise."

This risk of RJ morphing into a system of abuse and resulting in re-victimisation was also seen to extend beyond conference. RJP5 noted that, where there is an on-going relationship between a victim and offender,

"the risks are very high [after] leaving a conference [that the victim] is going right back into the same setting, [and this] could be, trouble because this controlling perpetrator has had the victim giving voice to him. That's what you're trying to do [in RJ]-trying to build a victim to be able to say that stuff. But you've got a high-end risk, when they leave. If the perpetrator has not got the accountability to be able to sit with what they're hearing, then they're going to be angry and then they're going to go out and do something."

Following on from this concern, some interviewees worried that victims may feel pressured by the RJ process into maintaining harmful relationships, even when this could result in further victimisation and harm. SLS3 explained that RJ could potentially act as a "conduit" for perpetrators to "gaslight" their victims, "adding to the emotional pressure on her [victim] that yes, he's done wrong and now he accepts it. He [says that] he will never do it again." This could place,

"pressure on her to either resume the relationship or continue the relationship. If that manipulation isn't picked up on. If he's a manipulative, controlling liar. If he doesn't mean it. He can get back together with her and he can continue his abuse. He could then use that in the future-oh that was behind us. That doesn't matter. I apologised for that. 
Anything he does or any engagement he has with her he uses against her in the future.

So yeah, I mean he can gaslight her about it."

Interviewees also expressed concern that RJ could be manipulated by perpetrator support persons, creating another pathway to re-victimisation and harm. RJP2 provided an example in which the current intimate partner of the offender had attended an RJ conference as a support person and sought to minimise the harm caused via a discourse of victim-blaming. RJP2 said, the offenders' "support people being involved" could pose a challenge to the RJ process." For example,

"new partners weighing in on situations, new partners helping to polarise, that's hard. I remember having one awful referral where the offence was like an historical offence that had happened 10 years ago or something and the offender had a new partner and she just painted the victim as like this horrible bitch who was just trying to destroy their lives. So, in that case you would say that the offender was able to use the conference to victim blame."

RJ practitioners reported that victims may lack support persons. This was seen as particularly problematic in the context of IPDFV cases where victims are often isolated and separated from family and peers as part of the coercive control by perpetrators. Interviewees also expressed concern over trauma caused by IPDFV/SV, which can result in victims experiencing negative self-schemas, intense shame, and self-blame around their victimisation. These issues manifested in RJ practitioners finding victim support persons difficult to source. RJP2 noted that it can be "a real challenge" because "often they [victims] are really embarrassed, might not have talked to family or friends about it, don't want anyone else involved. I guess that is the isolation part of it." Yet, several interviewees noted that support persons are crucial during RJ because they can help to alleviate the possibility of further psychological distress being caused to the victim.

Finally, it was noted that while the re-telling of victim stories was a key component of an RJ conference, this posed significant re-victimisation and re-traumatisation risks in IPDFV/SV cases. RJP1 noted that talking "about the specifics of [an SV] offence could be very distressing and cause re-victimisation." Similarly, RJP4 narrated, "I am always concerned about retraumatising people. I don't want to sit there and get the complainant to talk about [that]."

Power imbalances between victims and offenders, and the characteristics of many IPDFV/SV offenders, also raised concerns around victim voluntariness to participate. Interviewees questioned the ability of victims to freely, fairly, or effectively engage because they may feel or be pressured and manipulated into participating by perpetrators. RJP2 noted, "of course, offenders really want their matters to go to conference because then their charge will get discontinued." So, the "challenge that we're (RJ practitioners) often worried about, or very careful about is the offender being like, 'well, it's your fault again [if] I have to go to court.'" RJP1 noted that, in cases of familial SV, you needed to think about the possibility of "emotional manipulation" because participation in RJ should be,

"totally voluntary, it should be a decision-making of their own free will, and that they're not making that decision to make their parents happy, or to provide something to their brother [who has sexually victimised them]. You know that you're ruining their [perpetrator's] life and they share that sense of guilt. I find this to be a problem."

Further, victims may feel compelled by perpetrators into making agreements due to the on-going nature of their relationships. As noted by CCJ2, "we see a lot of people who want to maintain that relationship. So, who's to say that they're not going to agree to something just to please the respondent or the defendant." Where on-going relationships exist, victims may have learnt that, to avoid further victimisation, it is necessary to comply with perpetrator wishes and subvert their own. RJP4 explicated that "it becomes tricky. When we speak with victims [of IPDFV] it's not uncommon for a victim to say no, I'm okay. I just want to go ahead and do this, and things are all right, and I'm going to downplay exactly what has happened." 
Concern was also raised that, given histories of trauma and ongoing distress, victims may not be at liberty to advocate successfully on their behalf. RJP4 explained that, in their experience, sometimes "the victim [was] just not in a space, when you speak with them, they just can't keep it together. They're just not in a space where if it were to continue [with RJ] that you would just probably be inflicting more harm." Likewise, SLS3 noted that participating in RJ would be "a really hard thing for anyone to do, let alone someone [victim of IPDFV] with no self-esteem who has probably been abused for the last few years, is feeling horrible already and then she's getting the pile-on from everyone else about it."

In addition, enmeshment with perpetrators (i.e., economic, emotional, shared parenting responsibilities) may restrict free choice and participation. RJP1 stated that, in practice you need to know if "they (are) relying on people for financial support? I think that's something that needs to be taken into account, and it's really hard because they're embedded in their family. That's something that I would struggle with at times." RJP6 stated that, in her experience, "the IPDFV cases [are] just messy [because] they are enmeshed in each other's lives."

Interviewees also noted that, in the case of Indigenous IPDFV/SV, victims may face broader community pressure to participate in RJ. SLS3 narrated, "you do have to be careful. Is there pressure to agree to something like this because the community pressure is so great on them [perpetrators] not being sent jail or proceed with criminal justice approaches. I worry that women's individual safety is overtaken by community concerns."

\subsection{Perpetrator Accountability and Apologies}

Overall, concern regarding the ability of IPDFV/SV perpetrators to be accountable for their offending was narrated as being a significant challenge for RJ. As noted previously, IPDFV/SV offenders can be highly manipulative. IPDFV/SV perpetrators frequently deny responsibility for their conduct, blame their victims, minimise their behaviour, and lack empathy regarding the effect of their actions (Stark 2009). CCJ2 noted, "some of them are very sophisticated, they can easily lie through their teeth just to tick a box and use the system to get what they want." RJP4 concurred that some perpetrators "know that this is what they need to say in order to [undertake RJ]. They might give you lip service and say the right things but not really take accountability." RJP2 relayed that, "people who commit domestic violence" find "expressing themselves" and "taking responsibility for their actions" difficult. This was "really challenging" because "RJ is about expressing yourself [and] taking responsibility for your actions." This problem of accountability was seen to be compounded further in cases where perpetrators were neuro-atypical or had experienced significant trauma themselves.

Further, disquiet was expressed around perpetrators potentially using RJ to access victims. SLS3 noted, "you [could] have a hardened [IPDFV] criminal on the other side who's just using it for his own voyeurism, to get out of court and doesn't give a shit anyway." Likewise, RJP5 stated, "you have to really know that accountability is truly there or [are perpetrator expressions of accountability] just part of the grooming process to get back in, reintegrate themselves with the [victim]. You need to be really careful about that power and control." RJP5 said, "if they are a sexual offender [you might] actually [be] giving them the opportunity to, for want of a better word, hop on it again. You've really got to know that accountability is there."

These concerns around the ability of IPDFV/SV offenders to take accountability, coupled with the extreme power imbalance and trauma inherent in these types of offences, led some interviewees to question the applicability, authenticity, and safety of apologies provided as part of the RJ process. RJP3 reflected, "the defendant choking someone out or beating on them really badly [is] saying sorry really enough?" Further, apology in the milieu of IPDFV can be problematic because many victims will have previously experienced this as a controlling tactic used by offenders. Thus, apologies may be inauthentic and serve to perpetuate the cycle of abuse. CCJ2 stated, in reference to perpetrators of IPDFV, "so many times they'll commit an offence but then they'll apologise and then it will go back around 
in a circle. So, for them to sit there [in an RJ process] and apologise is not necessarily a reflection of them learning that what they have done is wrong."

The distinctive properties of IPDFV/SV including gendered power imbalances, perpetrator proclivities, and offending that frequently occurred over protracted periods within on-going intimate or familial relationships, resulted in some interviewees expressing misgivings that a singular RJ conference would make any headway in holding perpetrators accountable. Here, the true measure of accountability was perpetrator behavioural change, or evidence of commitment to this. SLS1 stated, "holding someone accountable is about meaningful behavioural change, that's years of work and so a one-off sort of process can't do that." However, RJP5 pointed out that is it not the job of RJ conferencing to rehabilitate offenders. Rather, it is about assessing their ability to be accountable as evidence by offenders "doing the work" pre-conference, e.g., through participation in offender change programs or other therapeutic intervention.

\subsection{One-Off Incident}

Uneasiness was articulated around RJ approaching IPDFV/SV as a 'one off' incident. Namely, only focusing on the offence that resulted in the process being initiated. This is problematic in cases of IPDFV because the violence is typically recurrent and escalates over time. RJP2 explicated that, in their experience, undertaking RJ in cases of "intimate partner DV" was "tough; they are really tough matters because we'll get a referral in relation to one incident, but for these people there's been, there might be years of behaviour."

\subsection{Facilitator/Convenor Neutrality}

Interviewees providing social and legal service to victims of IPDFV/SV relayed apprehension around the idea of facilitator/convenor neutrality and impartiality in IPDFV/SV cases. They argued that treating victims and offenders equally may uphold norms around structural gender inequality, reinforcing offenders' belief systems. SLS3 commented, "he has the power, if you're neutral in the face of violence then you're colluding with the perpetrator." However, RJP6 explained that, in practice, while facilitators/convenors were "impartial, the defendant [has] actually been charged. So, it's not neutral. It's not mediation. It's not two equal sides coming into the process."

\subsection{Broader Social-Structural and Symbolic Implications}

Interviewees voiced that there might be broader negative implications of utilising RJ in cases of IPDFV/SV. First, concern was expressed about RJ sending the wrong message to offenders, potential offenders, victims, and communities. SLS2 expressed, it is "important that we're not sending the message [to the community] that we are decriminalising domestic violence. It's taken such a long time for women to have domestic violence recognised as a criminal offence." There was further concern that RJ would be used as a 'dumping ground' for cases too difficult to prosecute. SLS1 said,

"I do think that there is real risk [that if] RJ really sort of blossomed and bloomed and the police actually became aware that it was an option... I can see real risk in a woman reporting to police and police going, 'oh that's a bit of a he said, she said case. It'll never get through court ... let's just send you off to RJ' and it really concerns me."

RJP6 explained that, "sometimes they [prosecutors] do actually refer [to RJ] to get rid of matters." It was therefore important to ensure that RJ was not construed or used as an alternative to conventional justice. Rather, it needed to work alongside conventional systems as an alternative justice response led by victims, not police or prosecutors. SLS2 asserted that "[RJ was] not decriminalising [DV] but just providing further options to victims." This made "community messaging important" to ensure that people understood that IPDFV/SV was being taken seriously.

Second, there was concern around the privatised nature of RJ. Unlike conventional justice, RJ takes place behind closed doors away from societal scrutiny. RJP3 expressed, “the community at large wouldn't be aware of a specific case. It's not in the media, being 
reported on so sometimes you're wondering, from a community perspective, have you done the right thing? What would the community think about that? Is that enough?" Further, bringing IPDFV/SV 'out of the shadows' is vital to denouncing these types of abuses and calling offenders to account. As noted by RJP1, IPDFV/SV "feed on isolation and secrecy [and] in my experience, adult RJ is still a somewhat privatised process divorced from community. As the process stands there is no opportunity for community to be involved in that accountability process." Some interviewees were fearful that privatising justice via RJ provided a convenient avenue for the State to divert responsibility for the problem of IPDFV/SV and save money. SLS3 explicated, "it [RJ] can be misused [by governments who may see it as] much cheaper than a criminal justice approach because you're not sending people to jail [and therefore] an attractive option. But it actually isn't cheap if you are going to do it properly."

\subsection{Indigenous Peoples}

Finally, and in addition to the challenges posed to victim voluntariness (discussed above), interviewees relayed that it might be difficult to engage Indigenous (i.e., Aboriginal and Torres Strait Islander) peoples in RJ, due to on-going community mistrust of nonIndigenous government and justice systems, as well as a lack of cultural efficacy. RJP2 noted that, in their experience, "it's been hard to get them to engage with us in the same way that a [non-Indigenous] client. We're the government [and do not have] those close relationships with the community." SLS1 reflected that,

"there is immense potential, but that really depends on your analysis of criminal justice, racism and how all of those things intersect. [Also] if I'm talking about the RJ process that I've seen and witnessed, there is huge work in terms of adding a cultural healing component that, as far as I can see, just isn't there."

\section{Best Practice: RJ for IPDFV/SV}

The challenges and concerns discussed above frequently elicited suggestions or explanations from participants as to how such problems were addressed, or should be addressed. For all interviewees, the first step to overcoming these issues and achieving best practice was to ensure that RJ operated from a victim centred position. A victim centred approach to justice "ensures that the needs and interests" of IPDFV/SV "victims are met, whenever possible, by giving victims a say in the process" and "extending them a degree of control and choice over how they want their justice needs met [i.e., empowerment]" (Centre for Innovative Justice 2014, p. 20). This is particularly important in IPDFV/SV cases because "the very nature of the offending can involve a removal of autonomy" (Centre for Innovative Justice 2014, p. 20). RJP2, noted "I think we are victim-focused but that could probably be [made] clearer that we will kind of make this commitment, that we're victim-focused and this is what we're all about, and design the process around the needs of the victim." What IPDFV/SV victims need from a system of justice must underpin the practice of RJ. Broadly speaking, and as discussed previously, this would incorporate victim empowerment, control, validation, safety, support, offender accountability and remorse, and ultimately healing from the harms caused by the offending.

Interviewees explained that it is crucial that $R J$ is a victim centred, supported and safe process. RJP6 stated that victims should "have full control [over] what they want to see happen. They [should] call the shots at all times." RJP1 explicated, "it is supposed to be a victim led process and a victim guarded [i.e., safe] process. We need to support people to really be able to make a decision that's based on their own needs." RJP5 noted, it "comes back to that support for the victim because part of the process is actually to empower that victim." Being victim centred necessitates process flexibility because the pathway to, and prioritisation of, victim needs will differ. It requires giving victims choice, and customising RJ accordingly. As explained by SLS2, if "it's about being victim focussed, we need to provide options for women to choose from. [RJ] has to be flexible." In keeping with the principle of victim centred justice, what a victim "wants or needs in terms of holding a 
perpetrator accountable needs to be firmly in the hands of the victim. Likewise, what do victims need around expressions of remorse? (SLS1). RJ was seen as a "conversation" that takes place on a "continuum," starting pre-conference, continuing through and postconference (RJP1). Suggestions, as narrated by the research participants regarding best practice at each stage are discussed below.

\subsection{Pre-Conference}

Interviewees narrated the centrality of pre-conference preparation to RJ best practice. As noted by SLS1, "it's actually about all the work that's done before that [conference]." This stage involved engaging and working with victims and offenders to prepare them for conference. It was described by RJP1 as the place where the "restorative conversations" start. Pre-conference preparation was not a one-off meeting, but a series of exchanges between facilitators/convenors, victims, offenders, and others (i.e., extended family, support persons, IPDFV/SV specialists working with both parties). It was a system of on-going preparation, assessment, and monitoring. RJP1 noted, "it's [the pre-conference stage] not a quick process. [With these cases it will be] somewhere between four to six months. The conference can only occur once you allow people that time to prepare."

The first best practice requirement during RJ's preparatory phase was the provision of information to victims and offenders about what the process would entail, so that informed participatory decision making could be made. RJP1 stated that "they need to fully understand what this process is, what is going to be expected of them. What could the potential outcomes [be], some of the risks that they might face" [and then] they need to be extended some time to consider this before making a decision about participating." Here, as noted by SLS1, it was important to be "transparent about the limitations of [RJ] and potentially what they're forgoing and giving up [by going through a RJ versus conventional criminal justice process]."

Second, the pre-conference phase was deemed central to developing a shared sense of the offending. This was important for ensuring a process where victims' experiences could be validated, and to avert the potential for victim-blaming, and, in turn, re-victimisation and re-traumatisation. SLS1 posited that RJ provided,

"opportunity to get clarity on the events and that's where a lot of the pre-work comes into it ... working with the perpetrator around accountability and getting clear with the survivor around their experience of what happened. All of that needs to be done before the conference, so there is this mutual shared sense of we're on the same page."

RJP1 concurred, stating that in their practice, "the actual offence behaviour [needs to be] established" during the preparatory phase. If it cannot be established, then the conference should not proceed. Further, there should be assessments of victims' needs, expectations (of the process), capacity to participate, safety, advocacy, and therapeutic requirements.

In terms of victim safety, SLS2 noted that the preparatory phase should comprise "a screening process where safety is discussed. Safety parameters around what this could mean for them [victims] in terms of attending RJ and afterwards." SLS2 suggested compiling a written formalised safety plan. This should be developed in close consultation with the victim, and discussed with, agreed to, and signed by the offender. In cases where there were on-going relationships between victims and offenders, and as noted by SLS1, these safety assessments would need to happen more than once: "there needs to be constant update because as with everything DV, the risks change very quickly, so that would need to be done throughout the process (leading up to conference day)."

Additionally, safety considerations should extend beyond the victim to include other potential or actual victims, i.e., children, other family members, current intimate partners, or others that the perpetrator may retaliate against. SLS2 explains,

"it's not always just the safety of that woman [current victim]. We see that happen frequently. Where he [perpetrator] is focussing that anger toward the previous partner 
onto the current partner. [Or] if the [perpetrator] is still having contact with the children [that he shares with the victim] and blaming them. It could really put those children at risk."

Support people may function as enablers for the offender, may have been complicit in or tacitly supportive of their behaviours, or pose other risks and problems for the victim. Thus, any proposed in-conference support people also needed to be assessed. In terms of offenders' support people, SLS2 articulated, "it may be family violence from his whole family. So, it's about that [pre-conference] screening." RJP1 noted that, pre-conference, they "would be working with the victim of the crime [and also] their support people [because] in our situation [the victim can still be] embedded with their family [and] the family attitudes and beliefs are so influential, we are wanting to try and intervene at that level as well." Thus, screening did not necessarily equate to the immediate ousting of support persons. Rather, it highlighted a potential issue to be addressed and worked on pre-conference.

Moreover, victims' needs and expectations, alongside their capacity to participate, should be established pre-conference. As noted by RJP1, this phase is about "supporting [victims] to really be able to make a decision that's based on their own needs and not where they are subsuming their needs to others." As explained by SLS1, to achieve this required,

"an understanding of the power dynamics going on in their lives. There are instances where [victims] might have a family member or partner who just wants to speak for them, they know what's right [for them] and those voices can be totally overbearing. [The victim's needs] aren't always the same [as the needs of others] so there can absolutely be a tension there ... it comes back down to power and control, and so the work needs to be done with the [victim pre-conference] to fully understand what it is they need" [and supporting] "them to express this."

SLS1 argued that it was especially important to establish what victims need in terms of justice, accountability, and apology:

"The starting point is let's have a conversation about justice. Really spending time with [victims] teasing out their own personal theory of justice and accountability. It requires quite a lot of groundwork and support so that they [victims] feel comfortable in knowing what accountability genuinely looks and feels like for them. It requires a nuanced analysis to be developed with the victim to understand their needs and how those might be addressed. [For example] what do they want in terms of an apology? What feels safe? What feels meaningful?"

Trauma histories can also create barriers to victim participation. Thus, the preconference phase should be used to establish strategies and work with victims to manage this. As noted by RJP1, "if people are becoming really distressed then they're not necessarily going to be able to [communicate effectively]."

Laying the groundwork for offender participation pre-conference was also vital. Here, supporting perpetrators to take accountability and demonstrate remorse via behavioural change was imperative. This would enable victims to receive validation, safety, and healing. As noted by SLS1, "for the perpetrator, it's initially assessing that capacity to take accountability and basically working on a curriculum [with them] for accountability." RJP1 noted that, where offending occurred over extended periods, offenders needed to be accountable for their on-going patterns of behaviour, not just the incident triggering the RJ referral. Offender ability to be accountable for their intention to offend, and postoffending responses (e.g., denials, victim blaming) were also important. RJP1 explained that perpetrators needed to be accountable for "setting up" the offending, and for their "behaviour afterwards as well." Thus, RJP1's preparatory practice involved working with offenders to establish a broader sense of accountability. Additionally, it was argued that RJ practitioners should be assessing offenders' co-occurring needs around substance abuse, trauma histories, mental health, and cognitive issues.

Assessing and working with victims and offenders pre-conference was not something that RJ practitioners should be doing alone. Rather, research participants explained this 
crucial foundational work needed to be undertaken in tandem with IPDFV/SV support services and therapeutic providers. While RJ convenors should have some IPDFV/SV expertise, their principal skill set is RJ, not gender-based violence. RJP2 noted that RJ should not be "sitting on its own" in these cases. RJP2 continues,

"it needs to be coupled with more stuff like behaviour change programs for men and counselling for women because we as convenors, we're not the experts in this [area], we're not therapists. Like [victims] may not be at that stage where they're recognising that they are in that cycle of violence [and] offender might be in total denial that they've got an issue and that they are participating in that cycle. It's not our space to kind of delve into that."

Thus, partnering with experts in IPDFV/SV was construed as vital to best practice. Here, as postulated by SLS2, IPDFV/SV specialists would work "with victims and offenders as part of the process to provide advocacy, support, and therapeutic intervention." RJP3 suggested that it would be helpful if "we partnered with a women's organisation that specialises in gendered violence." They suggested that it would be good to "have memorandums of understanding [with organisations and support providers who specialise in gender-based violence]. Like that would be the ultimate, if we had really close relationships with all these agencies and we had an agreement about how we were going to work together."

Collaborating with IPDFV/SV advocacy and support services in the preparatory RJ phase was deemed crucial to victim empowerment. RJP5 noted, "that support role leading into it is so vital because it about getting them [victims] ready and about empowering them so they do have a voice." SLS3 suggested that IPDFV/SV advocacy and support people attend RJ preparatory meetings, arguing "victims need an expert domestic violence counsellor or a sexual violence counsellor next to them." CCJ2 noted that "initially there needs to be engagement with a DV service to find out whether [the victim] is comfortable participating and whether it's appropriate for that person." SLS2 explained that victim engagement with IPDFV/SV specialists was a readymade avenue for assessing "victim risk and safety." This could change, particularly where there were on-going victim/offender relationships. Thus, IPDFV/SV advocacy and support services could deliver a case management approach by reassessing safety during pre-conference leadup.

Additionally, research participants expressed that, due to high levels of victim trauma, the need to ensure safety, voice, prevent process re-victimisation, and support healing, victims would ideally participate in pre-conference therapeutic intervention. RJP1 stated,

"in preparation for going into the conference we are looking at trauma history [so] the advocacy and support [should be] combined with a therapeutic response - trauma related therapeutic intervention. There needs to be some sort of opportunity for therapeutic connection. In case things are being triggered [by the RJ process]. How they [victims] tolerate conversations about the offences."

Likewise, RJP2 said, "I think that we should only be doing RJ after a victim has done counselling. As a convenor I've definitely had matters where I would love to be able to say well, the policy requires for you to do this and this, or the policy requires for you to have support person and to engage [in therapy] either in conjunction with this process or before we can do that process." However, as explained by RJP2, "I'm loathe to kind of apply one size fits all rules because each matter is so different and because [victims] might well be at different stages." Thus, there needed to be flexibility in the process to accommodate for variance in victim needs.

For offenders, the importance of IPDFV/SV experts working alongside RJ practitioners during the preparatory phase was also emphasised. It was argued that offender experts who understood the characteristics of, and power and control tactics employed by these types of offenders should be assessing perpetrator capacity to participate in the conference, and to take accountability for their harms in a way that will be meaningful for the victim. CCJ2 stated, 
"I do think somebody with experience in domestic and family violence needs to assess that person [perpetrator] for their suitability before they participate. They meet first and foremost with that person on a one-on-one basis, and then they do an assessment as to whether that person is suitable because if you're not trained in it, you're not going to pick up the nuances."

Similarly, RJP5 argued, "you've just got to be really careful about that power and control [in cases of SV]. I think, it would have to be a really strict intake process and format. You most likely need people who have experience with sex offenders."

However, participants argued that assessing offenders for conferencing could not be achieved through a one-off intake meeting. As noted previously by SLS1, it was about "working on a curriculum for accountability." Thus, perpetrators needed to be engaged in either an IPDFV/SV behavioural change program, or individualised therapy provided by a mental health professional with concomitant IPDFV/SV expertise. As noted by CCJ1, perpetrators need to be engaged with a therapeutic specialist in "men's behavioural change [because] they can gauge whether someone's legitimate [i.e., accountability]. They have [that insight as] someone trained in the field." RJP4 similarly noted that "there needs to be a better process where we can refer people to a specific program, not just a psychologist, but somebody who has that understanding of domestic violence where they can hold that person accountable." Therapeutic intervention for perpetrators was deemed an important precondition to participating in an RJ conference. RJP1 explicated that "we should [only] be doing RJ after [perpetrators] have been through a behaviour change program" because, as noted SLS1, "holding someone accountable is about meaningful behavioural change, a RJ process that works in tandem with behavioural change programs could offer that." It was through men's behavioural change programs and therapeutic intervention that toxic gender norms, behaviours, gendered inequality, and dominant notions of masculinity linked to controlling and aggressive behaviours, could be directly challenged.

\subsection{In Conference}

First, the timing of the conference was important. A conference can be a powerful healing tool used in conjunction with therapeutic intervention (occurring during the preconference stage, see above). RJP1 said, "sometimes it may be more helpful to have the conference earlier; linking it with motivation for perpetrator behavioural change or using it to "sustain this." Obviously, conferencing should only occur when both victims and offenders have been assessed and adequately prepared, in line with best practice (above).

Second, and pursuant to RJ being victim centred, victims should be given "lots of different methods or options for how they may wish to participate" in the conference [RJP1]. RJ does not always have to involve a face-to-face meeting between a victim and offender. Victim presence in RJ should be optional, and other alternatives considered. Interviewees narrated the following options: (1) a shuttle process; (2) provision of victim impact statements (written, audio or video recorded); (3) use of surrogate victims or victim representatives; (4) linking victims in via video or audio; (5) placing a screen between the victim and offender; and (6) allowing victims to come in for portions of the RJ conversation.

Third, interviewees considered facilitator/convenor numbers, gender, attendance of actors from the conventional criminal justice system, and support people. Some interviewees argued that ensuring victim emotional well-being and safety in IPDFV/SV conferences required a two-facilitator/convenor model. RJP1 stated,

"so you have one person who will lead the conversation. Who facilitates the meeting essentially and then they've got another person whose job is to attend to [conference] safety. While the convener who's doing the questioning is speaking with people, the other person can attend to how other people are responding. And so, then they can call attention to [any issues] and kind of check in. It's another set of eyes."

Ideally, and as noted by RJP2, "I could see it working as a bit of a hybrid situation where you had a female and a male convener working together." Some participants saw 
mixed gender conference facilitation as decisive for several reasons. It was argued that victims may feel more comfortable with a female facilitator/convenor. RJP5 noted, "I think generally, in my experience, women like to talk to women." Similarly, perpetrators may be more likely to open up to a male facilitator. CCJ2 stated that "a male's going to feel like he's being victimised [by a female facilitator/convenor]." RJP5 reflected that perpetrator accountability may be more likely with a "female conference facilitator," because "male facilitators" may be construed as "kind of a buddy ... it's a subconscious thing, you can see it [playing out in conferences], it's little, slight things that men do to men. Even that, 'all right mate, how're doing.' It's subtle stuff." SLS2 suggested that "men learn [better] from men so having a male, like a good [male] role model present in the room [is a good idea]." The key, however, was having "a good" male facilitator/convenor. SLS3 cautioned, "a man that's there [needs to be] from a victim perspective and understand the power dynamics of-understand the presentation of perpetrators." However, given that RJ in cases of IPDFV/SV needed to be victim centred, it was also noted that mixed gendered facilitation should only be used when "the woman is comfortable with that" [SLS2]. SLS1 argued that it might also be important to have Indigenous and LGBTIQ+ facilitators.

Participation in conference by actors from the conventional criminal justice system, namely police officers, was also deliberated by interviewees. It was expressed that having police in conferences would "give it an authoritative element" (RJP5). This could counteract concerns about the state divesting responsibility for justice, and communicate that IPDFV/SV was being taken seriously. Police presence could also be important for victim validation and the provision of safety (actual and a sense of). SLS2 reflected that,

"having that authority there could be a benefit, reassurance and validation for some victims. That police are part of this process and are listening. But also, for the [perpetrator] to see that police are part of this process. That this is their message from community and the state that their involved in this process and domestic violence is not okay."

However, it is not uncommon for victims of IPDFV/SV to have experienced failed police responses in the past (e.g., victims being blamed, safety needs being ignored, and perpetrators not being held accountable). This problem is likely exacerbated for Indigenous and other ethnic minority women who must also contend with racially discriminatory and oppressive police practices. Thus, SLS2 continues, "you might have other victims that will completely shut down because police are there. They've had very poor police responses. Then you have obviously CALD [culturally and linguistically diverse] women and Indigenous women and what that means for them seeing an officer there." Thus, whether police should be present in the conference needed to be assessed on a "case by case" basis, but "should be an option" decided by the victim (SLS2). SLS3 noted that, if a police officer was going to be involved, it needed to be someone "who's good, who takes a victim perspective. You could maybe use a [IPDFV/SV] specialist [police officer]."

As already discussed, support persons will have been adequately screened for suitability during the pre-conference phase (see previous). Suitable support people interpersonally connected to the victim, such as family and friends, were deemed important for victim well-being in conference. In addition, as was the case pre-conference, interviewees argued that specialised victim advocates would, ideally, be present. CCJ11 argued, "you need specialists advocating for the safety of the victims who understand victims, the cycle of DV, her safety [needs]. Having those people there at that conference would be good. The more support around a [victim] to prevent [re]victimisation and vulnerabilities the better as opposed to just having a RJ convenor to try and reach a resolution." RJP5 clarified that this was important because "it's that continuity of that person feeling that they are being supported and they can face a conference because they've got this person who has walked alongside them for the whole journey." Likewise, SLS2 stated that in the conference victims should have their "advocate, the DV specialist advocate that's been working with her throughout the whole process," if the victim wants them to "be present, that needs to be an option." 
Fourth, it was explicated that in-conference best practice should include close management of participant arrival and departures to ensure a safe (actual and sense of) process. Once again, achieving this was dependant on there being two facilitators/convenors present. RJP1 noted that you need to be "managing arrivals and departures," participants should be "scheduled to arrive at different times," and facilitators/convenors should be "waiting to receive people [to ensure] that there's not going to be any unintended encounters." Breaks should also be taken during conference. Participation in a RJ conference can be emotionally exhausting, there is a risk that perpetrators are engaging in subtlety manipulative power and control tactics obvious to the victim but not others, and given the trauma of IPDFV/SV, victims may not be coping as well as they appear to be. CCJ2 noted that there should be "constant breaks or check-ins during the [conference] to see how [the victim] is going, just making sure that they're not being influenced, [that they] are okay." CCJ2 noted, "during these breaks it would again be important to ensure victims and offenders were not coming into contact."

Fifth, while narrating the facts of an offence is a common in-conference practice utilised to hold offenders accountable, validate victims, and support healing, interviewees suggested this be reconsidered for IPDFV/SV. The reasons for this were two-fold. First, IPDFV/SV often involved multiple offence events. Thus, as noted by RJP1, "it could be hundreds of offences that have occurred over a number of years; you can't just give a story of the offence, it's not like on this day we were in the lounge and then this happened, and then I did that." Moreover, and as outlined previously, there was concern that in-conference offence narrations would result in re-victimisation. Offender accountability should have been established pre-conference.

To avert the possibility of re-victimisation in conference, storytelling may need to be bypassed altogether or adapted to be a recounting of the harm caused, and a general, rather than specific, discussion around offending patterns and escalations over time. RJP1 recounted that, in their practice, "they don't actually talk about the [offence] specifics [that] could be very distressing and cause re-victimisation [and] the offence facts should have been established [pre-conference]." RJP1 continues, "the storytelling is going to look different. It is more about looking at an established pattern of behaviour and maybe an escalation overtime." RJP5 reflected,

"maybe we need to look at our model and take that stuff [offence re-telling] out, because if we're going to do it under the model that exists now, then, to say to a rape victim, okay, tell me what happened, from what you remember, and then have to listen to the perpetrator recount-they're reliving it twice. So, the model would have to change. Maybe we don't do the reliving. Maybe we just talk about the harm. Maybe we talk about how that's going to affect the person, moving forward."

\subsection{Post-Conference}

It was argued that post-RJ follow-up with victims and offenders was essential. RJP1 said, "we have an ethical responsibility to continue to provide for these people." This ethical responsibly existed whether cases went to conference or not. RJP5 noted, "we need to provide a service on the back end [post-conference] as well."

For victims, post-conference follow through was imperative for safety, emotional well-being, and healing. However, once again, interviewees highlighted that facilitators/convenors were not IPDFV/SV victim advocates or therapists. SLS1 reflected, there "absolutely" needs to be on-going support mechanisms, but "it's like where does RJ end, and social work support start?" RJ is about delivering justice, and as such, cannot be expected to provide on-going therapeutic intervention while IPDFV/SV victim support, advocacy services, and therapeutic providers were ideally positioned to do so. Thus, it was incumbent on RJ practitioners to ensure victims were referred to appropriate postconference IPDFV/SV support. Ideally, victims will have been supported by IPDFV/SV service providers pre and during conference, allowing for continuity of care into the post-conference phase. RJP1 explained that, post-conference, victims "need to have that 
opportunity for follow up and ability to [therapeutically] process that experience. Things [could have been] triggered [by the conference]. That might need to be managed. And that's where having therapeutic support and those ongoing wrap around services [starting pre-conference] is really important."

Moreover, post-conference follow-up, support, and accountability mechanisms were seen as vital for offenders. CCJ2 argued that offender "follow-up through a men's behaviour change program or some sort of [specialised IPDFV/SV offender] counselling to see what they got out of the [conference] would [also] be good." As was the case with victims, offenders would have ideally been engaged in these programs, or with other offender specialists, since the pre-conference stage. For SLS2, post-conference was "about that monitoring around whether he [perpetrator] does fulfil what was agreed or if there is a relapse in offending and that sort of thing. I think that a very good thing with RJ would be to engage them [perpetrators] in these [offender change] programs and things like that." Thus, post-RJ through-care, and monitoring of offender compliance with conference agreements, should be done in partnership IPDFV/SV offender experts.

\section{Training}

As discussed at length above, interviewees were adamant that RJ should be operating in tandem with IPDFV/SV support services and therapeutic providers. Facilitators/convenors needed to be experts in RJ, not IPDFV/SV. Nevertheless, interviewees were clear that facilitators/convenors should be equipped with some expertise around IPDFV/SV to ensure efficacy of process in these types of cases. CCJ2 said, "definitely, I don't think you could do [RJ] without them having some sort of training." At a minimum, RJ facilitators/convenors should understand, and thus receive training around, the gendered power dynamics inherent in IPDFV/SV. This training should be mandatory, on-going, and conducted by specialists in IPDFV/SV victimisation and offending.

\section{Summary and Discussion}

In this paper, we presented findings from a qualitative (interview) study exploring the experiences and viewpoints of practitioners (conventional criminal justice actors and RJ practitioners) and IPDFV/SV service providers (social and legal) regarding the use of adult RJ conferencing in cases of gender-based violence. From the perspective of these practitioners and service providers we sought to: (1) understand what victims of IPDFV /SV need from a system of justice; (2) discern the perceptual benefits and challenges of utilising adult RJ conferencing in IPDFV/SV cases; (3) establish what a best practice adult RJ conferencing framework might encompass; and (4) identify the potential training needs of $\mathrm{RJ}$ conference facilitators/convenors.

In line with the previous RJ literature, our interviews strongly suggest that IPDFV/SV victims need a system of justice that extends them empowerment and control, where offenders are held to account, acknowledge their wrongdoing, and do not re-offend. Victims want reassurances of future safety for themselves and others. They need a justice system that does not exacerbate their isolation and trauma. Victims do not want to be blamed, silenced, or have their experiences trivialised. Further, justice environments should protect safety by not re-victimising or re-traumatising victims. Most participants in our study viewed conventional justice systems as failing victims in many, if not all, of these needs. For this reason, RJ presented as a better alternative.

However, interviewees highlighted numerous challenges in the use of RJ. These included: (1) concern that the inherent power imbalances characterising IPDFV/SV could be replicated in RJ, and that victimisation and harm may continue through and following the RJ process (see also Miller and Iovanni 2013; Mills et al. 2009; Proietti-Scifoni and Daly 2011; Rubin 2009; Edwards and Sharpe 2004; Silvester 2015; Stubbs 2004); (2) questions around whether victims were able to freely and effectively participate in the RJ process (see also Hooper and Busch 1996); (3) concerns over the ability of RJ to secure meaningful perpetrator accountability for victims (see also Cheon and Regehr 2006, Proietti-Scifoni 
and Daly 2011); (4) queries around the applicability, authenticity, and safety of apologies in RJ (see also Miller and Iovanni 2013; Silvester 2015; Stubbs 2010), (5) unease that during RJ, IPDFV may be viewed only as a one-off incident (see also Stubbs 2010); (6) concern that RJ facilitators/convenors may inadvertently collude with the perpetrator by not acknowledging or not being aware of ongoing coercion and control by offenders (see also Edwards and Sharpe 2004; Miller and Iovanni 2013; Mills et al. 2009; O'Donnell 2018); (7) apprehension over a lack of and subsequent need for basic training in IPDFV /SV best practice for RJ facilitators/convenors who work in these areas (see also Daly 2011); (8) disquiet over the lack of systematic integration of RJ with existing IPDFV and SV service providers and support networks towards goals of increased victim support and enhanced offender accountability; (9) need for more flexibility for victims throughout the entire RJ process, including RJ conferences (see also Gavrielides 2015; Jülich and Thorburn 2017); (10) questions and concerns around victim voluntariness the cultural efficacy of RJ, including Indigenous distrust of non-Indigenous justice systems (see also Nancarrow 2006); and (11) trepidation that utilising RJ in cases of IPDFV/SV may have broader community ramifications, including that: RJ would become a dumping ground for cases too difficult to prosecute, dealing with IPDFV/SV through RJ may be perceived as too lenient or as a 'get out of jail free card' for perpetrators (see also Curtis-Fawley and Daly 2005), society was being excluded from justice, and RJ presented as a convenient way for the State to divest itself from responsibility (see also Hudson 2002; Miller and Iovanni 2013; Mills et al. 2009; Proietti-Scifoni and Daly 2011; Silvester 2015; Stahlman 2017).

Our research also identified steps that could be taken to overcome many of these challenges through a best practice framework underpinned by a victim centred approach committed to empowerment, safety, and healing. RJ was viewed as being a conversation that takes place on a continuum, starting pre-conference, continuing through, and postconference.

The pre-conference phase was deemed central to the success of RJ. Here, best practice included: (1) RJ knowledge provision and protections around informed participatory decision making (see also Rubin 2009); (2) developing a shared sense of the offending, safety planning (see also Daly 2011; Rubin 2009); (3) establishing the needs and expectations of victims alongside their capacity to participate; (4) laying the groundwork for offender engagement by establishing an accountability curriculum; and (5) undertaking assessments of co-occurring needs. Crucially, assessing and working with victims and offenders preconference needed to be undertaken in partnership with IPDFV/SV support services and therapeutic providers (see also Gavrielides 2015).

In conference, interviewees noted that victims needed to be extended better choices in how they wanted to participate (e.g., shuttle process, etc.) (see also Gavrielides 2015). There was strong support for the use of two facilitators/convenors to ensure process safety and efficacy. Further, mixed gender conference facilitators/convenors and participation of suitably qualified police officers should be available as requested by victims. Interviewees also noted the need for participation from suitable support people for victims, determined during the pre-conference stage. In-conference breaks should be taken. Victims and offenders should be closely managed during arrival, departure, and interval periods to ensure safety. Unless victims explicitly request otherwise, in conference recounting of the offence details should be adapted to a discussion of the harm caused or a general, rather than specific, conversation around offending patterns and escalations over time. Victims should also have the option of bypassing the storytelling phase altogether, requiring instead that accountability be taken and demonstrated by the offender in pre-conference meetings between the offender, facilitators/convenors, and IPDFV/SV experts.

Post-conference follow-up with victims and offenders was considered central to best practice. Here, it was incumbent on RJ practitioners to ensure victims and offenders were referred to appropriate post-conference IPDFV/SV support. Facilitators/convenors should, again, be working in partnership with offender services and therapeutic providers to monitor compliance with agreements and bolster on-going behavioural change. Finally, 
although RJ for IPDFV/SV should be operating in tandem with qualified support services and therapeutic providers throughout the process, facilitators/convenors still required focussed IPDFV/SV training.

Lastly, while there is growing discussion on the use of RJ in cases of gender-based violence, there remains a much smaller number of empirical studies examining the issue. This makes the research reported in this paper important because it adds to and advances the knowledge base in this under-explored area. However, the current research only explored the perspectives of a specific group of people, about a particular RJ program, operating in one Australian city. It is therefore important that further locale specific research be undertaken. Further, while this research provided much needed insights about RJ and gender-based violence from the experiences and perspectives of key conventional criminal justice system actors, IPDFV/SV service providers and RJ practitioners, it did not include victims or offenders. Obviously, the perceptions and experiences of both these groups are important to understanding the efficacy of RJ in this space and their voices should be included in future research.

Author Contributions: Conceptualization, S.J.; methodology, S.J.; formal analysis, S.J.; data collection, S.J., W.R.W. and T.R.; writing—original draft preparation, S.J.; writing—review and editing, S.J., W.R.W. and T.R. All authors have read and agreed to the published version of the manuscript.

Funding: This research received no external funding.

Institutional Review Board Statement: The study was conducted according to the guidelines of the Declaration of Helsinki and approved by the Institutional Review Board (or Ethics Committee) of Griffith University (protocol code GU Ref No: 2020/397 on June 2nd, 2020).

Informed Consent Statement: Informed consent was obtained from all subjects involved in the study.

Data Availability Statement: The data presented in this study are available on request from the corresponding author. The data are not publicly available due to privacy and ethical restrictions.

Acknowledgments: The authors would like to thank the research participants for their time and Richard Dening, for his support and commitment to justice for victims of gendered violence.

Conflicts of Interest: The authors declare no conflict of interest.

\section{References}

Alexander-Scott, Michaeljon, Emma Bell, and Jenny Holden. 2016. Shifting Social Norms to Tackle Violence against Women and Girls. London: UKaid.

Australian Institute of Health and Welfare. 2018. Family, Domestic and Sexual Violence in Australia, 2018; Canberra: Australian Institute of Health and Welfare.

Beck, Gayle, Judiann McNiff, Joshua Clapp, Shira Olsen, Megan Avery, and Houston Hagewood. 2011. Exploring Negative Emotion in Women Experiencing Intimate Partner Violence: Shame, Guilt, and PTSD. Behavior Therapy 42: 740-50. [CrossRef]

Bennice, Jennifer, Patricia Resick, Mindy Mechanic, and M. Millie Astin. 2003. The Relative Effects of Intimate Partner Physical and Sexual Violence on Post-Traumatic Stress Disorder Symptomatology. Violence and Victims 18: 87-94. [CrossRef]

Buchbinder, Eli, and Zvi Eisikovits. 2003. Battered Women's Entrapment in Shame: A Phenomenological Study. American Journal of Orthopsychiatry 73: 355-66. [CrossRef]

Centre for Innovative Justice. 2014. Innovative Justice Responses to Sexual Offending: Pathways to Better Outcomes for Victims, Offenders and the Community. Melbourne: RMIT University.

Cheon, Aileen, and Cheryl Regehr. 2006. Restorative Justice Models in Cases of Intimate Partner Violence: Reviewing the Evidence. Victims and Offenders 1: 369-94. [CrossRef]

Coker, Donna. 2006. Restorative Justice, Navajo Peacemaking and Domestic Violence. Theoretical Criminology 10: 67-85. [CrossRef]

Commonwealth of Australia. 2009. The Cost of Violence against Women and Their Children; Canberra: The National Council to Reduce Violence againsts Women and Their Children.

Curtis-Fawley, Sarah, and Kathleen Daly. 2005. Gendered Violence and Restorative Justice: The Views of Victim Advocates. Violence against Women 11: 603-38. [CrossRef] [PubMed]

Daly, Kathleen, and Elena Marchetti. 2012. Innovative Justice Processes. In Crime and Justice: A Guide to Criminology. Edited by Marinella Marmo, William de Lint and Palmer Darren. Sydney: Lawbook. 
Daly, Kathleen. 2011. Conventional and Innovative Responses to Sexual Violence; Canberra: Australian Institute for the Study of Sexual Assault.

Edwards, Alan, and Susan Sharpe. 2004. Restorative Justice in the Context of Domestic Violence: A Literature Reivew. Alberta: Mediation and Restorative Justice Centre.

Enander, Viveka. 2010. A Fool to Keep Staying: Battered Women Labeling Themselves Stupid as an Expression of Gendered Shame. Violence against Women 16: 5-31. [CrossRef]

Gavrielides, Theo. 2015. Is Restorative Justice Appropriate for Domestic Violence Cases? Revista de Asistenta Sociala 4: 105-21.

Hooper, Stephen, and Ruth Busch. 1996. Domestic Violence and Restorative Justice Initiatives: The Risks of a New Panacea. Waikato Law Review 4: 101-29.

Hopkins, Quince, Mary Koss, and Karen Bachar. 2004. Applying Restorative Justice to Ongoing Intimate Violence: Problems and Possibilities. Saint Louis University Public Law Review 23: 289-311.

Hudson, Barbara. 2002. Restorative Justice and Gendered Violence: Diversion or Effective Justice? British Journal of Criminology 42: 616-34. [CrossRef]

Jones, Loring, Margaret Hughs, and Ulrike Unterstaller. 2001. Post-Traumatic Stress Disorder in Victims of Domestic Violence: A Rewiew of the Research. Trauma, Violence, E Abuse 22: 99-119.

Joudo-Larsen, Jacqueline. 2014. Restorative Justice in the Australian Criminal Justice System; Canberra: Australian Institute of Criminology.

Jülich, Shirley, and Natalie Thorburn. 2017. Sexual Violence and Substantive Equality: Can Restorative Justice Deliver? Journal of Human Rights and Social Work 2: 34-44. [CrossRef]

Koss, Mary. 2006. Restoring Rape Survivors: Justice, Advocacy, and a Call to Action. Annals of the New York Academy of Sciences 1087: 206-34. [CrossRef]

Miller, Susan, and LeeAnn Iovanni. 2013. Using Restorative Justice for Gendered Violence: Success with a Postconviction Model. Feminist Criminology 8: 247-68. [CrossRef]

Mills, Linda, Mary Maley, and Yael Shy. 2009. Circulos De Paz and the Promise of Peace: Restorative Justice Meets Intimate Violence. New York University Review of Law E Social Change 33: 127-52.

Nancarrow, Heather. 2006. In Search of Justice for Domestic and Family Violence: Indigenous and Non-Indigenous Australian Women's Perspectives. Theoretical Criminology 10: 87-106. [CrossRef]

Nettleton, Clare, and Heather Strang. 2018. Face-to-Face Restorative Justice Conferences for Intimate Partner Abuse: An Exploratory Study of Victim and Offender Views. Cambridge Journal of Evidence-Based Policing 2: 125-38. [CrossRef]

O'Donnell, Samantha. 2018. Proceed with Caution: Restorative Justice and Domestic Violence. In Pandora's Box, Law in the First Person: Indigeneity and the Law. Edited by Julius Moller and Molly Thomas. Brisbane: University of Queensland.

Presser, Lois, and Emily Gaarder. 2000. Can Restorative Justice Reduce Battering? Some Preliminary Considerations. Social Justice 27: 175-95.

Proietti-Scifoni, Gitana, and Kathleen Daly. 2011. Gendered Violence and Restorative Justice: The Views of New Zealand Opinion Leaders. Contemporary Justice Review 14: 269-90. [CrossRef]

Queensland Government. 2019. Adult Restorative Justice Conferencing. Available online: https://www.qld.gov.au/law/legalmediation-and-justice-of-the-peace/settling-disputes-out-of-court/restorative-justice/about (accessed on 16 November 2020).

Rubin, Pamela. 2009. A Community of One's Own? When Women Speak to Power about Restorative Justice. In Restorative Justice and Violence against Women. Edited by James Ptacek. New York: Oxford University Press.

Silvester, Sophie. 2015. The Need for Prudent Courage: A Literature Review of Family Violence and Restorative Justice Practices in Aotearoa-New Zealand. Wellington: Victoria University.

Stahlman, Avila. 2017. Restorative Justice in the Context of Intimate Partner Violence: Suggestions for its Qualified Usage as Supplementary to the Criminal Justice System. University of Florida Journal of Law and Public Policy 28: 194-213.

Stark, Evan. 2009. Coercive Control: How Men Entrap Women in Personal Life. Oxford: Oxford University Press.

Stubbs, Julie. 2002. Domestic Violence and Women's Safety: Feminist Challenges to Restorative Justice. In Restorative Justice and Family Violence. Edited by Heather Strang and John Braithwaite. Cambridge: Cambridge University Press.

Stubbs, Julie. 2004. Restorative Justice, Domestic Violence and Family Violence. Canberra: Australian Domestic and Family Violence Clearinghouse.

Stubbs, Julie. 2010. Relations of Domination and Subordination: Challenges for Restorative Justice in Responding to Domestic Violence. University of New South Wales Law Journal 33: 970-86.

Suzuki, Masahiro, and William Wood. 2017. Co-option, Coercion and Compromise: Challenges of Restorative Justice in Victoria, Australia. Contemporary Justice Review 20: 274-92. [CrossRef]

Wager, Nadia. 2015. Restorative Justice and Domestic Violence: A View from a Positive Victimological Perspective. In Positive Criminology. Edited by Natti Ronel and Dana Segev. Oxon: Routledge.

Wood, William R., and Masahiro Suzuki. 2016. Four Challenges in the Future of Restorative Justice. Victims and Offenders 11: 149-72. [CrossRef]

Wood, William R., and Masahiro Suzuki. 2020. Are Conflicts Property? Re-Examining the Ownership of Conflict in Restorative Justice. Social and Legal Studies 29: 903-24. [CrossRef]

World Health Organization. 2013. Global and Regional Estimates of Violence against Women. Geneva: World Health Organization. 